Journal of Clinical Investigation

Vol. 41, No. 5,1962

\title{
CONTINUOUS MEASUREMENTS OF INTRAVASCULAR OXYGEN TENSION IN NORMAL ADULTS *
}

\author{
By STEVE T. KOEFF, M. U. TSAO, ATTILA VADNAY, THOMAS O. WILSON AND \\ JAMES L. WILSON
}

(From the Department of Pediatrics and Communicable Diseases, University of Michigan, Ann Arbor, Mich.)

(Received for publication November 10, 1961 ; accepted February 1, 1962)

The purpose of this report is to record our studies on the degree of normal fluctuation of oxygen tension in arterial and venous blood of healthy adults while they breathed room air and during the administration of oxygen. These changes were measured by an oxygen electrode, which records blood oxygen tension continuously and responds immediately to changes in the tension. The electrode was devised by two of the authors, Tsao and Vadnay, in this laboratory (1).

Until the recent development of continuously recording oxygen electrodes, investigations involving direct measurement of oxygen tension in blood depended on the findings from isolated single blood specimens. Interpretation of such data was limited to that oxygen tension present in the blood vessel during the actual moment of blood withdrawal. It was assumed that such findings represented a mean oxygen tension for the individual under the conditions studied and that fluctuations around this mean would be trivial. Because of variations that can occur normally in the respiratory pattern, it was our belief that these changes might be reflected in the arterial oxygen tension. This would result in a range of fluctuation of the level of arterial oxygen tension such that a single measurement might be of less significance than had been thought.

The advantage of the direct measurement of oxygen tension over its estimation from the measurement of hemoglobin saturation is obvious. Under the conditions of most studies the measurements of hemoglobin saturation occur at the flat upper portion of a hemoglobin-oxygen dissociation curve, where changes of oxygen tension do not significantly change the percentage of hemoglobin

\footnotetext{
* Supported by Grant H-2556 (C-4), United States Public Health Service, Bethesda, Md. Presented in part at the Midwestern Society for Pediatric Research, November 2, 1960, Milwaukee, Wis.
}

saturation, or small changes in the percentage of hemoglobin saturation may reflect very great changes in blood oxygen tension $(2,3)$. Numerous other conditions which modify the estimation of oxygen tension from hemoglobin saturation are practically immeasurable simultaneously as will be discussed later, so that only relatively crude estimations of oxygen tension can be made.

Continuously recording oxygen electrodes have been developed in several laboratories $(4,5)$. Some are now commercially available, ${ }^{1}$ and investigations using them have been reported (6). The electrode used in these studies is of platinum which is hydrostatic and hydrodynamic pressureinsensitive, has a collodion membrane that does not require an electrolyte solution between the membrane and electrode, and is almost instantaneous in its response to changing oxygen tension. It is adapted to the conventional needle hubs and requires only $0.5 \mathrm{ml}$ of blood per minute of usage. With this device we studied a group of normal young adults and have obtained continuous measurements of arterial oxygen tension while they were in a resting state breathing room air, and during breath holding and hyperventilation. Measurements were also obtained during the breathing of oxygen-enriched atmospheres. Another group was studied with peripheral (antecubital) venous oxygen tension measurements in room air and during oxygen administration. Simultaneous measurements were made with this electrode and the Clark electrode as a further check of our quantitative measurements.

\section{METHODS AND MATERIALS}

Subjects. The subjects were male and female university students and laboratory personnel, whose ages ranged from 24 to 33 years. All were free of cardio-

${ }^{1}$ Beckman, Spinco Div., Beckman Instruments, Inc., Standford Industrial Park, Palo Alto, Calif. 
pulmonary or other disease and were in good physical condition.

Preparation and calibration of the electrode. A venous blood sample was obtained from the subject 1 hour before the experimental procedure. The blood was equilibrated with gases containing 5 per cent carbon dioxide and oxygen of three different concentrations in a modified Severinghaus-Bradley tonometer bath. The oxygen concentrations of these gases had been previously analyzed with the Scholander Micro-gas analyzer. The equilibrated blood was then used to calibrate the continuously recording electrode. Several polarographic recordings were obtained from 0 to $-0.9 \mathrm{v}$ and these polarograms were examined for integrity of the collodion membrane over the platinum surface of the electrode, as detailed by Tsao and Vadnay (1). The electrode was then calibrated at $-0.7 \mathrm{v}$ with the three gases. Initially, calibrations of the electrode were done before and after each procedure. Because of the stability of the electrode calibration, we subsequently calibrated the electrode only once during each experiment. Thus the recorded oxygen tension could be quickly calculated during each procedure.

The Clark electrode (4), in conjunction with the Severinghaus-Clark circuit, was calibrated with blood equilibrated with the same three gases. The results were plotted to give a calibration curve for each subject's blood.

Arterial blood studies. The subject was instructed in the experimental procedures to be performed. $\mathrm{He}$ was encouraged to relax and requested not to speak unless it was necessary to do so once the experiment had started. With the subject supine, and with the left arm outstretched and supported, the antecubital area over the brachial pulse was infiltrated with 1.5 per cent procaine solution. The arterial puncture was made and $3 \mathrm{ml}$ of blood withdrawn anaerobically in a heparinized syringe sealed with mineral oil for $\mathrm{pH}$ and $\mathrm{CO}_{2}$ content determinations which were done immediately. The $\mathrm{PCO}_{2}$ was calculated from these results. The methods of this laboratory for these determinations have been previously described (7). The values obtained were within the normal limits.

Before the syringe was removed a good flow of blood and proper placement of the needle was assured. Once the syringe was removed the adaptor containing the electrode was attached, and the continuous recording of the blood oxygen tension begun. The apparatus was as described by Tsao and Vadnay (1) with one exception: the channel through which the heparin solution was injected during the withdrawal of blood has been moved down the adaptor to a position below the tip of the electrode. This change has helped to prevent clotting on the membrane of the electrode. The heparin $(4 \mathrm{~g}$ per $100 \mathrm{ml}$ solution) is injected in a dilution of heparin to blood, 1: 100 . This volume is small enough to produce no detectable variation in the oxygen tension of the blood. The respiratory pattern was recorded simultaneously with the arterial oxygen tension on a Gilson multichannel recorder. This was done with a Phipps-Bird pneumograph belt about the subject's chest and was recorded via a Statham transducer.
During an experiment, blood was withdrawn at a constant rate of $0.5 \mathrm{ml}$ per minute by means of a Harvard infusion-withdrawal pump, and the blood oxygen tension was recorded with a Sargent polarograph. In some experiments, when a steady polarographic current from the electrode had been achieved, the electrode assembly was momentarily detached for withdrawal of $3 \mathrm{ml}$ of blood anaerobically in a preheated $\left(37^{\circ} \mathrm{C}\right)$ heparinized syringe. This syringe, previously sealed with mineral oil, was jacketed in a plastic shield to aid in maintenance of temperature of the blood sample. The blood was immediately introduced into the cuvet of the Clark electrode and the oxygen tension measured. This was done for a comparison of the quantitative levels of oxygen tension as measured by the two systems.

After recording the arterial oxygen tension while the subject breathed room air, 50 per cent or 100 per cent oxygen, or both, was administered by face mask. The time of application of the mask was noted on the record. Oxygen inhalation was continued until the arterial oxygen tension had stabilized at its higher level. The record was again marked the instant the face mask was removed and oxygen discontinued. Further gas administration was delayed until the blood oxygen tension returned to a stable, lower level. The second concentration, 50 or 100 per cent, was given by the same technique.

Some subjects were asked to hyperventilate by deep, rapid respiratory efforts. After hyperventilation, the subject was asked to hold his breath as long as possible.

We have measured repeatedly the time lag due to the dead space of our electrode system; i.e., the time lapse between blood flow at the needle tip, which lies within the lumen of the artery, and the electrode tip, within the adaptor housing, where the blood oxygen tension produces the current in the polarographic record. This interval is 10 seconds in all of our records. Since the response time of the electrode itself is for all practical purposes instantaneous (1), the dead space produces a 10-second lag in the recording of the blood oxygen tension. We have measured the circulation time between pulmonary events and time of change in the left brachial artery and found this to be between 4 and 12 seconds, which agrees with the circulation times of other techniques (8).

Once the artery was entered, the necessary precautions were taken to prevent hematoma formation. Throughout the procedure the artery was palpated, and when the needle was removed, pressure was applied to occlude the peripheral radial pulse for five minutes. The subject was observed for another 15 minutes. We have had no complications with this technique.

Venous blood studies. The subjects were studied as described above except that the antecubital vein was used. The arm was at the level of the heart, and the vein was entered without the use of a tourniquet. The subject either sat or was supine, and no local anesthesia was used. Recording techniques and oxygen administration were the same except that only 100 per cent oxygen was used. 


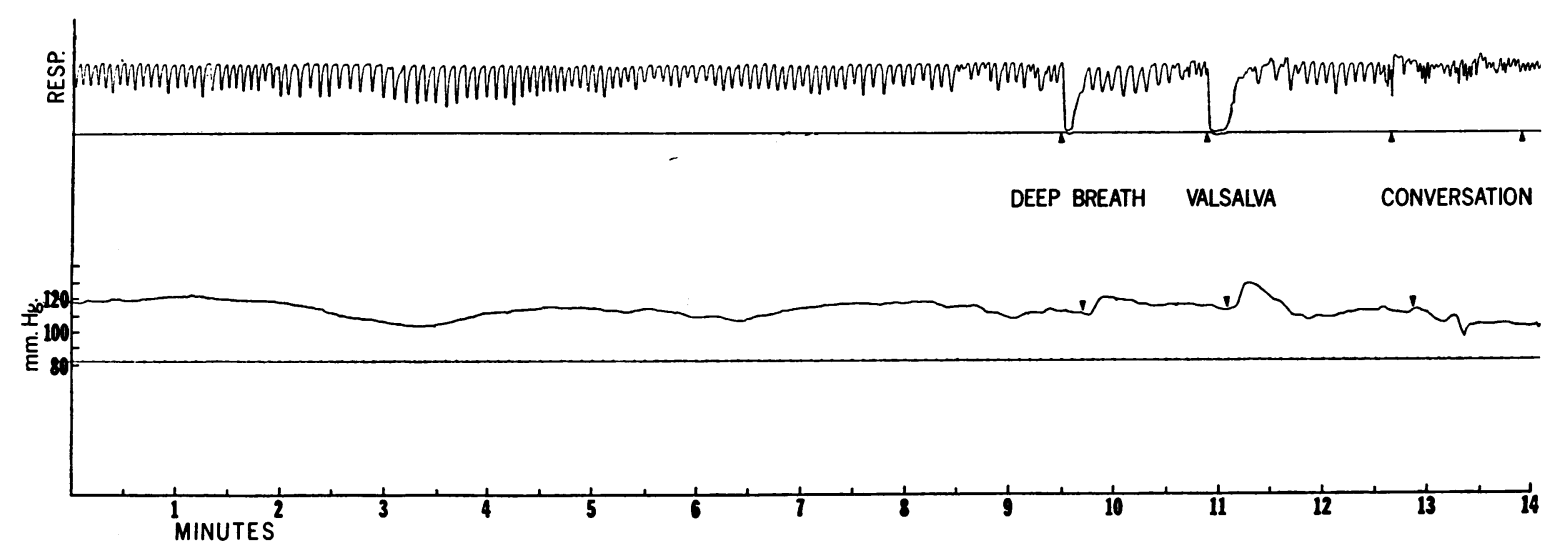

Fig. 1. Simultaneous continuous Recording of ARTERial oxygen tension and Respiratory pattern of A SUPINE, RELAXED INDIVIDUAL BREATHING ROOM AIR. The arrows indicate simultaneous events. The oxygen tension record lags behind the respiratory record by 10 seconds because of the dead space of the electrode. From 0 to $9.5 \mathrm{~min}-$ utes, range of arterial $\mathrm{Po}_{2}, 105$ to $117 \mathrm{~mm} \mathrm{Hg}$ (relationship to respiratory changes are obvious). At deep breath, arterial $\mathrm{Po}_{2}$ increases $10 \mathrm{~mm} \mathrm{Hg}$. At Valsalva, at end of deep inspiration, arterial $\mathrm{Po}_{2}$ increases $17 \mathrm{~mm} \mathrm{Hg}$. At conversation, arterial $\mathrm{Po}_{2}$ fluctuations are over a range of $16 \mathrm{~mm} \mathrm{Hg}$.

\section{RESULTS}

Breathing room air. Simultaneous recordings of continuous measurements of arterial oxygen tension and respiratory pattern of a typical subject are shown in Figure 1. As can be seen, the arterial oxygen tension is not at a constant level, but fluctuates in a gentle, changing pattern over a range of about $20 \mathrm{~mm} \mathrm{Hg}$, which was the average

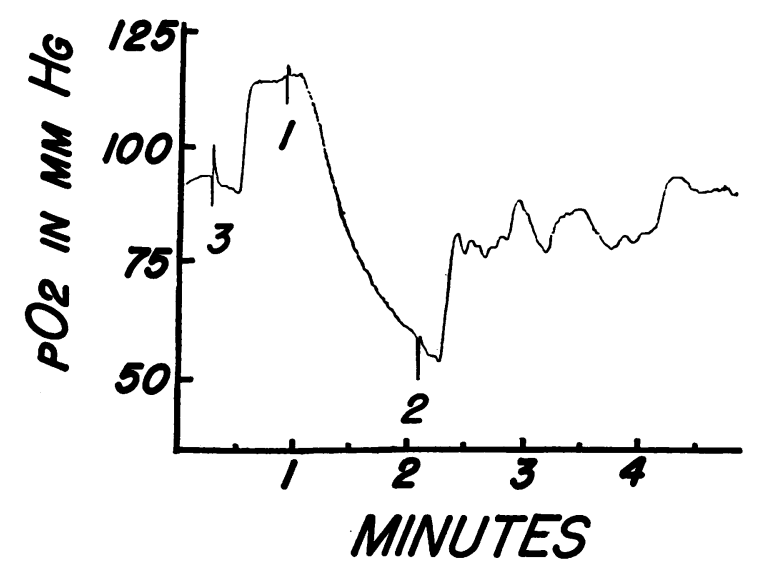

Fig. 2. EFFECT OF BREATH HOLDING AND HYPERVENTILATION ON ARTERIAL OXYGEN TENSION WHILE SUbJECT L.S. BREATHES ROOM AIR. 1, Voluntary apnea; 2, recovery with normal respiration; 3 , hyperventilation. Time lag after each marking is a summation of dead space of the electrode and the circulation time. Hyperventilation, 36 seconds, arterial $\mathrm{Po}_{2}$ increased $21 \mathrm{~mm} \mathrm{Hg}$. Breath holding, 72 seconds, arterial $\mathrm{Po}_{\text {. }}$ dropped 51 $\mathrm{mm} \mathrm{Hg}$. for our subjects. These fluctuations are synchronous with the changes in the respiratory pattern. The measured levels of arterial oxygen tension in our normal subjects under the conditions of the experiment have been as low as 69 and as high as $125 \mathrm{~mm} \mathrm{Hg}$. Several subjects have had repeated studies, and the mean values of the range of ar-

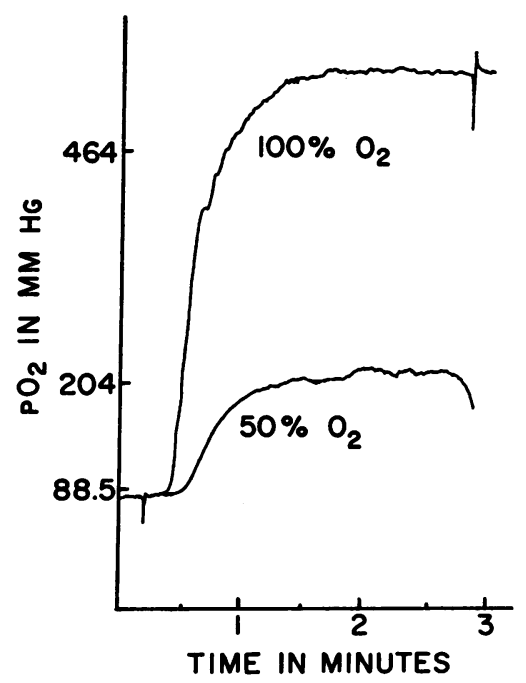

Fig. 3. Polarographic ReCords of Continuous measUREMENT OF ARTERIAL OXYGEN TENSION OF TWO INDIVIDUALS WITH THE ADMINISTRATION OF 50 AND 100 PER CENT oXYGEN. Polarographic deflection indicates the time of application of the face mask. The interval between this deflection and the upswing of the arterial oxygen tension represents the 10 -second dead space of the electrode plus the circulation time to the left brachial artery. 
terial oxygen tension on the two occasions have differed by $20 \mathrm{~mm} \mathrm{Hg}$ or more.

Any event that alters the respiratory pattern abruptly will produce sudden changes in arterial oxygen tension. A single deep breath, a cough, the Valsalva procedure, and even simple conversation are shown to alter the arterial oxygen tension markedly. A deep breath improves alveolar ventilation, and a cough and the Valsalva maneuver increase intrathoracic pressure, producing an elevation of the arterial oxygen tension. Conversation produces irregular alterations in breathing pattern with concomitant increase and decrease in the arterial oxygen tension dependent
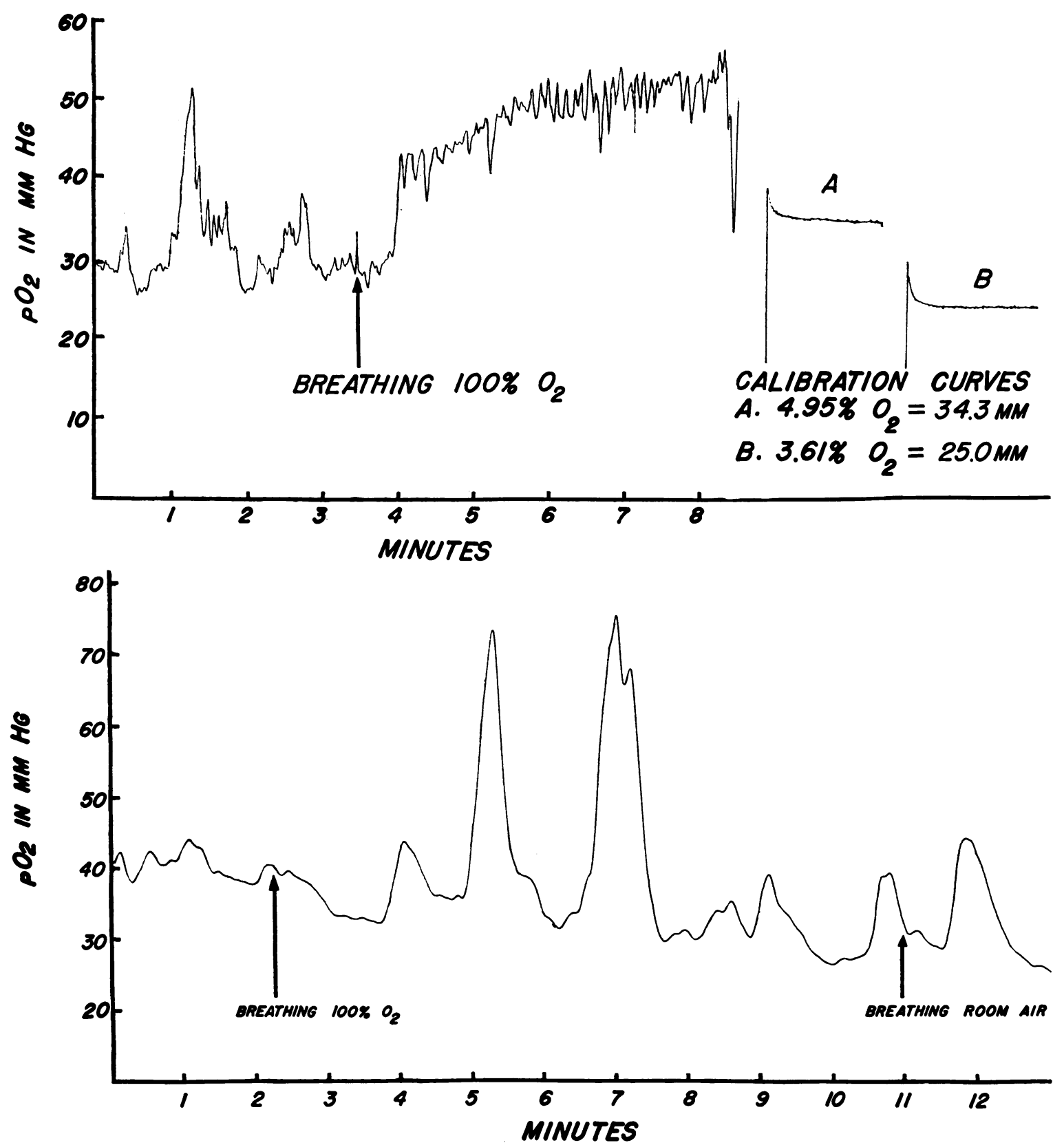

Fig. 4. Polarographic records of continuous measurements of anteclbital venous oxygen tension with 100 PER CENT OXYGEN ADMINISTRATION BY FACE MASK; FOUR TYPES OF RESPONSE CAN BE SEEN. 

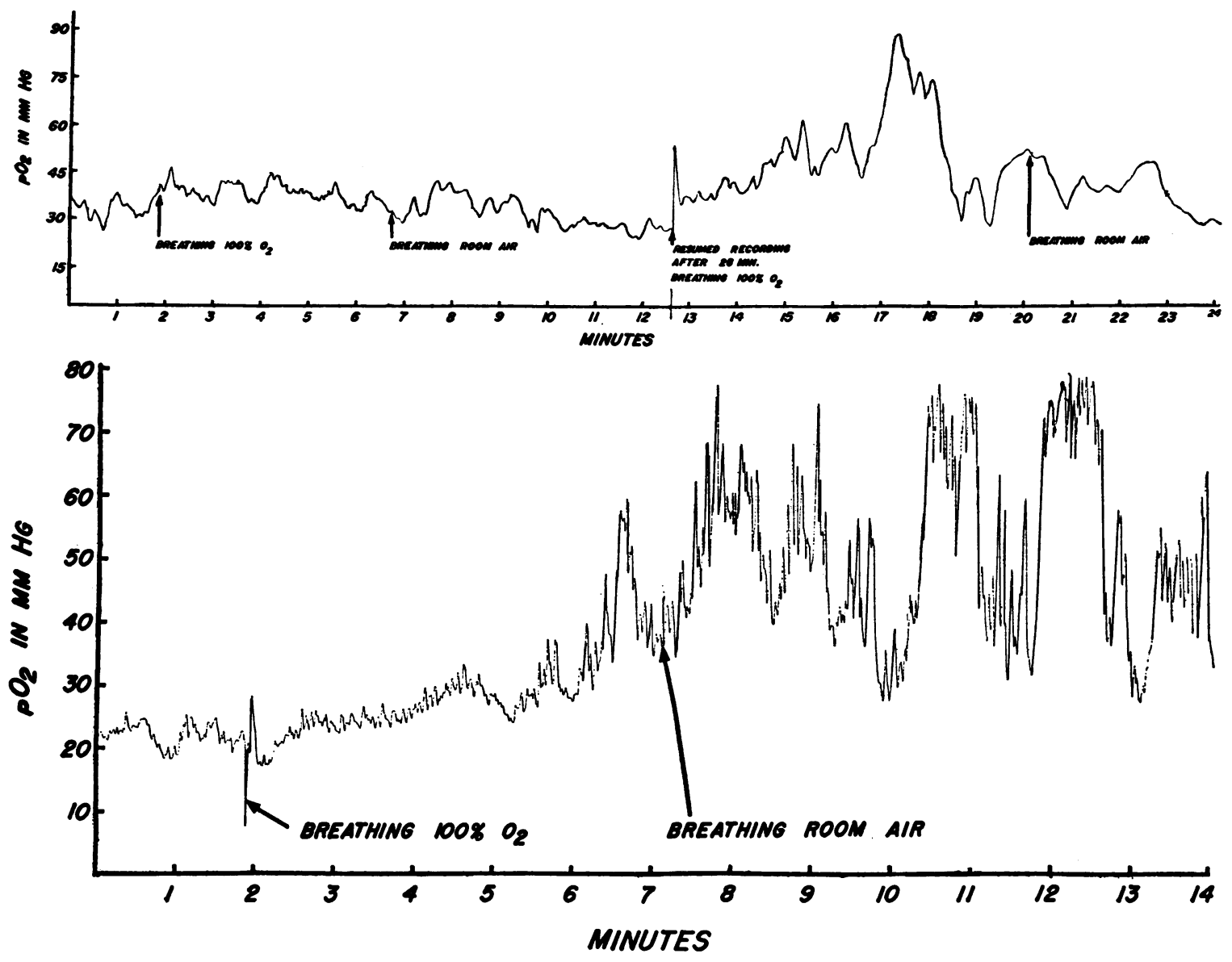

FIG. 4.-(Continued)

on the respiratory change. An occasional subject is capable of maintaining marked regularity in breathing pattern, and in this situation the fluctuations in arterial oxygen tension are minimal.

Figure 2 is a record of a subject who voluntarily hyperventilated and then held his breath as long as possible. As can be seen, hyperventilation can produce an increase in the arterial oxygen tension as great as $21 \mathrm{~mm} \mathrm{Hg}$. During hyperventilation with deep, rapid breaths, there is an improved intrapulmonary mixing of gases and increased $\mathrm{CO}_{2}$ removal, producing an increase in the aveolar oxygen tension. This is reflected in an increase in the arterial oxygen tension. With breath holding, the degree of fall in arterial oxygen tension seems directly related to the duration of the apnea. As oxygen is being removed from the alveoli during apnea, the oxygen tension in the alveolus falls rapidly, and this is reflected in a rapid fall in the arterial oxygen tension. The longest period of apnea was in Subject F.F. who had just breathed 50 per cent oxygen. He held his breath 108 seconds with a resulting drop of arterial oxygen tension of $85 \mathrm{~mm} \mathrm{Hg}$. The ability for prolonged breath holding after oxygen breathing has been noted by others (9). A summary of the degree of change with hyperventilation and breath holding is found in Table I.

Breathing 50 per cent and 100 per cent oxygen. Typical records of changes in arterial oxygen tension during inhalation of either 50 or 100 per cent oxygen by face mask are reproduced in Figure 3. With the administration of oxygen the arterial oxygen tension rises rapidly initially and then slows to a plateau related to the inspired oxygen concentration. This plateau is usually reached in 60 to 90 seconds.

When added oxygen is discontinued the arterial 
TABLE I

Changes in arterial oxygen tension in normal adults in hyperventilation and in breath holding

\begin{tabular}{|c|c|c|c|c|}
\hline \multirow[b]{2}{*}{ Subject } & \multicolumn{2}{|c|}{ Hyperventilation } & \multicolumn{2}{|c|}{ Voluntary apnea } \\
\hline & Time & $\begin{array}{l}\text { Increase } \\
\text { in } \mathrm{Po}_{2}\end{array}$ & Time & $\begin{array}{c}\text { Decrease } \\
\text { in } \mathrm{PO}_{2}\end{array}$ \\
\hline & $\sec$ & $m m \mathrm{Hg}$ & $\sec$ & $m m \mathrm{Hg}$ \\
\hline F.F. & 40 & 20 & $\begin{array}{r}39 \\
108\end{array}$ & $\begin{array}{l}37 \\
85\end{array}$ \\
\hline $\begin{array}{l}\text { L.S.S. } \\
\text { B.B. } \\
\text { J.S. } \\
\text { J.S. } \\
\text { K.L. }\end{array}$ & $\begin{array}{l}36 \\
42 \\
60 \\
42 \\
36\end{array}$ & $\begin{array}{l}21 \\
19 \\
20 \\
13 \\
16\end{array}$ & $\begin{array}{l}72 \\
66 \\
78 \\
30 \\
60\end{array}$ & $\begin{array}{l}51 \\
68 \\
43 \\
18 \\
36\end{array}$ \\
\hline
\end{tabular}

oxygen tension falls. However, the rate of fall is somewhat slower than is the rate of increase. Return to levels of breathing room air is accomplished over 3 to 4 minutes, and the immediate low point is at an oxygen tension that frequently is lower than the preoxygen level. As others have noted (10), some subjects tend to breathe more slowly and more shallowly with added oxygen. In these subjects the change in breathing pattern persists for a few minutes after the oxygen is discontinued, resulting in the lower arterial oxygen tension. However, within a few minutes in room air, the respiratory pattern returns to the preoxygen levels. Such rebound lowering of arterial oxygen tension was not noted in all of our subjects after the discontinuance of added oxygen. Table II shows the mean measurements of arterial oxygen tension of some of our subjects who breathed 50 and 100 per cent oxygen.

Changes in venous oxygen tension with 100 per cent oxygen administration. Figure 4 shows four polarographic records of the changes of venous oxygen tension found in the antecubital veins of subjects who breathed room air and 100 per cent oxygen for short intervals. These demonstrate the individuality and unpredictability of the re-

\begin{tabular}{|c|c|c|c|c|c|}
\hline \multirow[b]{2}{*}{ Subject } & \multirow[b]{2}{*}{ Sex } & \multicolumn{2}{|c|}{$\begin{array}{l}\text { Breathing } \\
\text { room air }\end{array}$} & \multirow[b]{2}{*}{$50 \% \mathrm{O}_{2}$} & \multirow{2}{*}{$\begin{array}{l}100 \% \\
\mathrm{O}_{2}\end{array}$} \\
\hline & & $\overline{\text { Low }}$ & $\overline{\text { High }}$ & & \\
\hline $\begin{array}{l}\text { F.F } \\
\text { L.S. } \\
\text { K.L.1 } \\
\text { B.S. } \\
\text { J.S. }\end{array}$ & $\begin{array}{l}\mathbf{M} \\
\mathbf{M} \\
\mathbf{F} \\
\mathbf{F} \\
\mathbf{M}\end{array}$ & \multirow[t]{2}{*}{$\begin{array}{r}120 \\
76 \\
89 \\
69 \\
93 \\
72 \\
88\end{array}$} & \multirow[t]{2}{*}{$\begin{array}{r}125 \\
93 \\
104 \\
87 \\
95 \\
80 \\
100\end{array}$} & $\begin{array}{l}331 \\
321 \\
253 \\
223\end{array}$ & \multirow[t]{2}{*}{$\begin{array}{l}681 \\
661 \\
474 \\
690 \\
662 \\
690\end{array}$} \\
\hline K.L.2 & F & & & 216 & \\
\hline
\end{tabular}

sponse in peripheral venous oxygen tension of subjects given 100 per cent oxygen. The four types of response are: slight elevation in venous oxygen tension with the breathing of 100 per cent oxygen; little change in venous oxygen tension except for an occasional spike-like elevation; virtually no change in venous oxygen tension unless carried over a long period of time; and no change in venous oxygen tension during inhalation of 100 per cent oxygen but elevated tensions once oxygen has been discontinued.

Comparison of arterial oxygen tensions measured with the continuous recording electrode and with the Clark electrode. During several experi-

TABLE III

Comparison of blood oxygen tension with the continuously recording electrode and the Clark electrode*

\begin{tabular}{|c|c|c|}
\hline $\begin{array}{c}\text { Gas } \\
\text { breathed }\end{array}$ & $\begin{array}{l}\text { Po, Clark } \\
\text { electrode }\end{array}$ & $\begin{array}{l}\text { Po, } \text {, cont. rec. } \\
\text { electrode }\end{array}$ \\
\hline$\% \mathrm{O}_{2}$ & $m m \mathrm{Hg}$ & $m m \mathrm{Hg}$ \\
\hline 20.9 & 91.7 & $86.5-91.3$ \\
\hline 100.0 & 591.5 & 591.0 \\
\hline 20.9 & 84.0 & 86.5 \\
\hline 20.9 & 104.9 & 97.0 \\
\hline 20.9 & 91.0 & 93.0 \\
\hline 20.9 & 101.5 & 99.0 \\
\hline 20.9 & 77.0 & 76.0 \\
\hline 20.9 & 100.0 & 102.8 \\
\hline 50.0 & 236.6 & 205.0 \\
\hline 20.9 & 111.0 & 117.0 \\
\hline 20.9 & 78.4 & 80.5 \\
\hline 50.0 & 322.4 & 331.0 \\
\hline 20.9 & 115.3 & 112.2 \\
\hline
\end{tabular}

* Blood samples for the Clark electrode were obtained during periods of relative stability of arterial oxygen tension as measured by the continuous microelectrode.

mental situations, our microelectrode was momentarily disconnected and a sample of blood was withdrawn anaerobically and immediately analyzed with the Clark electrode. The sample was then equilibrated with the same gases used for the calibration of the continuously recording electrode, and the calibration curve of the Clark electrode was established. In almost every instance the levels with the Clark electrode were within the range of the microelectrode at the time of removal of the blood sample. These comparisons are found in Table III.

\section{DISCUSSION}

Prior to the development of techniques permitting continuous recording of blood oxygen tension, investigators concluded that the range of normal 
values for arterial oxygen tension was narrow and that fluctuation was slight (11-16). Using the dropping-mercury electrode, we had studied normal children and adults (17) and obtained widely separated values on different occasions in the same subject under presumably similar conditions. These results forced us to question the interpretation of single arterial oxygen tension measurements and to entertain the possibility of fluctuating levels in the normal subject. With the more recent development of techniques permitting multiple rapid analyses, this belief in the stability of arterial oxygen levels has been altered (3), but until the development of equipment that recorded blood oxygen tension continuously, these changes could not be well demonstrated.

Many factors influence the level of circulating arterial oxygen tension. The concentration of the oxygen in the atmosphere, the barometric pressure, the status of pulmonary ventilation, the diffusibility of the alveolar-capillary membrane, the presence of cardiac or extracardiac shunts as well as the cardiovascular status, and the type of hemoglobin and its concentration are among the most obvious $(10,18-20)$. There are also characteristics to be remembered about the hemoglobin-oxygen dissociation curve which has positional shifting produced by changes in $\mathrm{pH}, \mathrm{P}_{\mathrm{CO}_{2}}$, electrolyte concentrations, temperature, and the type of hemoglobin (i.e., fetal hemoglobin). Of all the potential causes for change in arterial oxygen tension, the one that would probably be most influential in the quiet resting state is change in the respiratory pattern. The other factors would very likely remain rather stable in the resting state. We have shown that fluctuations in arterial oxygen tension in the resting state do occur, and these can be almost exactly correlated with the variations in the respiratory pattern. Sudden changes in breathing, such as a single deep breath, a cough, the Valsalva procedure, and even conversation influence the level of the arterial oxygen tension. Such changes might not be noted in single sample techniques. Breath holding and hyperventilation frequently occur, owing to apprehension during the time of blood sampling and during vessel puncture, and these markedly influence the level of arterial oxygen tension. Thus, if exact values of blood oxygen tension are of importance, one should have some concern for the interpretation of measurements with single-sample techniques where these normal variations cannot be detected.

The effects of hyperventilation and of voluntary apnea have been previously investigated $(3,9$, 21-23). Our findings are similar to those of others, but we are able to record the changes as they occur. With hyperventilation, our subjects demonstrated an early rapid elevation in arterial oxygen tension with leveling at a new point of equilibrium. This is not unexpected, since pulmonary factors of mixing and distribution would be improved with hyperventilation which improves alveolar ventilation and thus produces the increased alveolar oxygen tension. With breath holding, the degree of fall in arterial oxygen tension is related to the duration of the apnea. It is of interest to note that when arterial oxygen tensions reached levels as low as $60 \mathrm{~mm} \mathrm{Hg}$ with voluntary apnea, we did not observe cyanosis of the skin or mucous membranes. These levels are probably too transient to produce visible cyanosis. Once the arterial oxygen reached low levels, our subjects could no longer hold their breath.

With the breathing of oxygen-enriched gases, we observed the following responses in arterial oxygen tension. Within 4 to 12 seconds of application of the face mask, the brachial arterial oxygen tension began its rise. Vasicka and co-workers (24), using the Beckman microelectrode, and Heller and Watson (25), using the Kruezer modification of the Clark electrode, have reported rates of increase in arterial oxygen tension with the administration of 100 per cent oxygen. All of our subjects reached arterial oxygen equilibration with the gas breathed within 1.5 minutes of application of the face mask. This is comparable with the 2 minutes reported by Heller and Watson, rather than the 5 minutes reported by $\mathrm{Va}$ sicka. The levels we achieved were higher than those reported by Heller and Watson, but their subjects were anesthetized in preparation for surgery. We recognize that the levels of oxygen tension reached are somewhat higher than have been reported with breathing of 100 per cent oxygen, but we recalibrated the electrode, and its response had not changed during the studies. We had no technique to monitor the arterial carbon dioxide tension simultaneously at the time. However, hyperventilation was an unlikely factor, since many subjects breathed more slowly and shallowly in 
100 per cent oxygen than they did in room air. We do not think that hyperventilation is responsible for these high levels. With discontinuance of the oxygen by face mask, the arterial oxygen tension returned to its new equilibration in room air within 2 to 4 minutes. Thus, by measurements of the arterial oxygen tension, any prolonged effect with short periods of oxygen breathing on arterial oxygen tension could not be detected.

It is recognized that when the oxygen tension of blood of a peripheral vein, such as the antecubital vein, is measured, the level of such tensions is dependent upon the status of the tissues and the capillary bed distal to the vein and drained by it. Thus, factors of oxygen requirement and uptake by these tissues, the vasomotor state of the capillary bed, and the rate of flow of blood through the capillaries from the arterial side, will influence the oxygen tension of venous blood. Heat will dilate the capillary bed and "arterialize" venous blood. A drop in oxygen tension of the tissues will also dilate the capillaries and increase blood flow through the tissues, while an increase in arterial oxygen tension will cause constriction and decrease blood flow through systemic capillary beds (10). Because of these variables, recorded measurements of venous oxygen tension in peripheral veins are few. Lambertsen and coworkers (26) have reported only slight increase in internal jugular oxygen tension even when oxygen is given under several atmospheres of pressure, unless a vasodilator such as carbon dioxide is added to the gas breathed. We found slight elevations in venous oxygen tension, as did Lambertsen, when our subjects breathed oxygen. However, the changes that occurred were variable and unpredictable. With 100 per cent oxygen breathing, four different patterns of change in venous oxygen tension occurred: 1) slight elevation in venous oxygen tension; 2) little change except for an occasional spike; 3) virtually no change unless the study was carried over a long period of time; and 4) no change during oxygen breathing, but an increase in venous oxygen tension for a few minutes after the oxygen was discontinued. In all subjects the condition of the extremity was the same; supported, outstretched, inactive, and at room temperature. Interpretation of these findings will not be attempted, since no other observations were made. However, these rec- ords do emphasize the variability of responses in venous oxygen tension resulting from the inhalation of oxygen.

The values obtained by simultaneous measurement of arterial oxygen tension with the continuously recording oxygen electrode and the Clark electrode further serve to support the accuracy of the method used in these experiments.

\section{SUMMARY}

1. Arterial oxygen tension is influenced by multiple factors, but in the resting state it is most influenced by changes in the respiratory pattern. It can be shown that the arterial oxygen tension in normal adults, while breathing room air at rest, usually fluctuates over a range of 10 to $20 \mathrm{~mm} \mathrm{Hg}$. Any activity that changes the breathing pattern, such as a single deep breath, a cough, and so forth, will change the arterial oxygen tension. The effects of breath holding and hyperventilation on the arterial oxygen tension can be considerable.

2 . With the administration of 50 or 100 per cent oxygen, the brachial arterial oxygen tension starts to rise within 4 to 12 seconds, and a new point of equilibrium with the respired gas is reached within 1 to 1.5 minutes. With the discontinuance of oxygen breathing, only 2 to 4 minutes are required for the arterial oxygen tension to return to its previous level. Thus, any prolonged effects of breathing oxygen are not evident by arterial blood levels.

3. Peripheral venous oxygen tensions were measured in subjects given 100 per cent oxygen. Four patterns of response were noted.

4. Continuous recording of blood oxygen tension is more informative, particularly when coupled with a recording of the respiratory pattern, than are methods using single blood samples for analyses. Arterial oxygen tension can change rapidly with sudden changes in respiration, and these changes may be missed with single-sample techniques. Such changes may occur during the period of blood withdrawal, leading to erroneous interpretations in situations where absolute values are of importance.

\section{REFERENCES}

1. Tsao, M. U., and Vadnay, A. An electrode for continuous measurement of transient blood $\mathrm{pO}_{2}$ in the vessel. J. appl. Physiol. 1960, 15, 712. 
2. Nahas, G. G., Morgan, E. H., and Wood, E. H. Oxygen dissociation curve of arterial blood in men breathing high concentrations of oxygen. J. appl. Physiol. 1952, 5, 169.

3. Heller, M. L., and Watson, T. R., Jr. Polarographic study of arterial oxygenation during apnea in man. New Eng1. J. Med. 1961, 264, 326.

4. Clark, L. C., Jr., Wolf, R., Granger, D., and Taylor, Z. Continuous recording of blood oxygen tensions by polarography. J. appl. Physiol. 1953, 6, 189.

5. Kruezer, F., Harris, E. D., Jr., and Nessler, C. G., Jr. A method for continuous recording in vivo of blood oxygen tension. J. appl. Physiol. 1960, 15, 77.

6. Said, S. I., Banerjee, C. M., Davis, R. K., and Crosier, J. L. Continuous in vivo recording of arterial blood $\mathrm{pO}_{2}$ using a needle electrode. Fed. Proc. 1961, 20, 422.

7. Reardon, H. S., Graham, B. D., Wilson, J. L., Baumann, M. L., Tsao, M. U., and Murayama, M. Studies of acid base equilibrium in premature infants. Pediatrics 1950, 6, 753.

8. Knutson, J. R. B., Taylor, B. E., Ellis, E. J., and Wood, E. H. Symposium on in vivo photometry of blood in human beings. Studies on circulation time with the aid of the oximeter. Proc. Mayo Clin. 1950, 25, 405.

9. Klocke, F. J., and Rahn, H. Breath holding after breathing of oxygen. J. appl. Physiol. 1959, 14, 689.

10. Comroe, J. H., Jr., and Dripps, R. D. The Physiological Basis for Oxygen Therapy. Springfield, I11., Thomas, 1950, p. 95.

11. Comroe, J. H., Jr., and Dripps, R. D., Jr. The oxygen tension of arterial blood and alveolar air in normal human subjects. Amer. J. Physiol. 1944, $142,700$.

12. Lilienthal, J. L., Jr., Riley, R. L., Proemmel, D. D., and Franke, R. E. An experimental analysis in man of the oxygen pressure gradient from alveolar air to arterial blood during rest and exercise at sea level and at altitude. Amer. J. Physiol. 1946, 147, 199.

13. Riley, R. L., Lilienthal, J. L., Jr., Proemmel, D. D., and Franke, R. E. The relationships of oxygen, carbon dioxide, and hemoglobin in the blood of man: Oxyhemoglobin dissociation under various physiological conditions. J. clin. Invest. 1946, 25, 139.

14. Lambertsen, C. J., Bunce, P. L., Drabkin, D. L., and Schmidt, C. F. Relationship of oxygen tension to hemoglobin oxygen saturation in the arterial blood of normal men. J. appl. Physiol. 1952, 4, 873.

15. Filley, G. F., Gregoire, F., and Wright, G. W. Alveolar and arterial oxygen tensions and the significance of the alveolar-arterial oxygen tension difference in normal men. J. clin. Invest. 1954, 33, 517.

16. Binet, L., Bour, H., Bochet, M., and Barrès, G. La tension partielle des gaz $\left(\mathrm{O}_{2}\right.$ et $\left.\mathrm{CO}_{2}\right)$ dans le sang artérièl. Interêt et limites de son exploration en clinique. J. Physiol. (Paris) 1956, 48, 949.

17. Graham, B. D., Koeff, S. T., Tsao, M. U., Sloan, C., and Wilson, J. L. Direct plasma oxygen tension determination in infants and adults in air and in modified atmospheres (abstract). Amer. J. Dis. Child. 1959, 98, 593.

18. Riley, R. L., and Cournand, A. Analysis of factors affecting partial pressure of oxygen and carbon dioxide in gas and blood of lungs: Theory. J. appl. Physiol. 1951, 4, 77.

19. Fowler, N. O., Smith, O., and Greenfield, J. C. Arterial blood oxygenation in sickle cell anemia. Amer. J. med. Sci. 1957, 234, 449.

20. Rodman, T., Close, H. P., and Purcell, M. K. The oxyhemoglobin dissociation curve in anemia. Ann. intern. Med. 1960, 52, 295.

21. DuBois, A. B. Alveolar $\mathrm{CO}_{2}$ and $\mathrm{O}_{2}$ during breath holding, expiration, and inspiration. J. appl. Physiol. 1952, 5, 1.

22. Weitzner, S. W., King, B. D., and Ikezono, E. The rate of arterial oxygen desaturation during apnea in humans. Anesthesiology 1959, 20, 624.

23. Farhi, L. E., and Rahn, H. Gas stores in the body and the unsteady state. J. appl. Physiol. 1954-55, $7,472$.

24. Vasicka, A., Quilligan, E. J., Aznar, R., Lipsitz, P. J., and Bloor, B. M. Oxygen tensions in maternal and fetal blood, amniotic fluid, and cerebrospinal fluid of the mother and baby. Amer. J. Obstet. Gynec. $1960,79,1041$.

25. Heller, M. L., and Watson, T. R., Jr. Arterial oxygenation during transition from 100 per cent oxygen to air breathing: Polarographic $\mathrm{paO}_{2}$ study. Anesthesiology 1961, 22, 385.

26. Lambertsen, C. J., Kough, R. H., Cooper, D. Y., Emmel, G. L., Loeschcke, H. H., and Schmidt, C. F. Oxygen toxicity. Effects in man of oxygen inhalation at 1 and 3.5 atmospheres upon blood gas transport, cerebral circulation and cerebral metabolism. J. appl. Physiol. 1952, 5, 471. 